\title{
TPMT and DPD polymorphisms: Efficient screening method for Indian patients considering taking Thiopurine and 5-FU drugs
}

\author{
T.F. Ashavaid*, Rani Raghavan, Swarup Shah, Asha Kapadia, Sachin Almel and Devendra Desai \\ Research Laboratories, P.D. Hinduja National Hospital \& Medical Research Centre, Mumbai, India
}

\begin{abstract}
Introduction: Development of DNA-based tests for TPMT/DPD polymorphisms can help clinicians and patients to make important decisions about cancer treatment. Also, due to lack of Indian data, we aimed at the development and validation of these tests in Indian patients.

Materials and Methods: Molecular assays were used for identifying TPMT/DPD variations; validated by DNA sequencing. Results: Molecular assays have been used for screening TPMT*2, *3A, *3B, *3C alleles and IVS14+1(G $\rightarrow \mathrm{A})$ in DPD gene. A patient, exhibiting neutropenia on 6-MP was observed to be G460A-homozygote, while, two Acute Lymphoblastic Leukemia (ALL) patients with side-effects exhibited wild-type alleles. Two patients showing 6-MP side-effects and responding well to the same drug at later stage also carried wild-type alleles.

Discussion: G460A homozygosity in a patient allowed clinicians to stop 6-MP treatment, improving patient's health status. Two ALL patients showing side-effects were wild-type, indicating presence of unidentified rare variations. Two patients with wild-type allele showed side-effects during 6-MP treatment, but responded well to same drug at later stage, suggesting side-effects to be attributable to multiple biological and environmental processes. Absence of IVS14 $+1(\mathrm{G} \rightarrow \mathrm{A})$ in DPD gene will not exclude possibility of another mutation.

Conclusion: Molecular assays for determining common TPMT/DPD variations, can provide accurate diagnosis and efficient therapies in future clinical studies.
\end{abstract}

Keywords: Chemotherapy, cancer, genetic tests, SNP's, A719G, G460A, G238C, IVS14+1(G $\rightarrow$ A), acute lymphoblastic leukemia (ALL), azathioprine, pharmacogenomics, PCR, toxicity, diagnosis

\section{Introduction}

One of the main goals to improve chemotherapy in cancer patients is to increase the safety, while not reducing the efficacy of therapy. Chemotherapeutic drugs are administered at a fixed dosage based on either body sur-

${ }^{*}$ Corresponding author: Dr. T.F. Ashavaid, Consultant Biochemist, Head, Dept. Laboratory Medicine, Jt. Director Research, P.D.Hinduja National Hospital \& Medical Research Centre, Veer Savarkar Marg, Mahim, Mumbai, 400 016, India. Tel: +91 22 24447935; Fax: +91 22 24442318/24447309; E-mail: dr_tashavaid @hindujahospital.com. face area or weight. However, these compounds have a very narrow therapeutic index. Approximately, $7 \%$ of the patients are affected by adverse drug reactions. The inter-individual genetic variations have been reported to have a major impact on drug activity. These genetic variations are the result of multiple mechanisms such as single nucleotide polymorphisms (SNP's) (over 90\%), insertions, deletions, tandem repeats and microsatellites [5].

A pharmacogenetic test that can identify these variations can help the clinicians as well as the patients to make important decisions about treatment options for cancers. 
In this study, we have developed pharmacogenetic tests for 2 of the most widely used chemotherapeutic drugs, viz: 6-Mercaptopurine (6-MP) and 5Fluorouracil (5-FU). 6-MP is an antimetabolite drug that oncologists have been using for more than 30 years to treat Acute Lymphoblastic Leukemia (ALL), autoimmune disorders and inflammatory bowel disease.

Thiopurine Methyltransferase (TPMT) is an important enzyme in the biotransformation of 6-MP, thioguanine and azathioprine drugs. These drugs undergo metabolic activation to form active thioguanine nucleotides (TGN), which interfere with DNA replication and stop rapidly growing cancer cells from further growth. However, it is of utmost importance that the excess drug gets inactivated so that the growth of the normal cells is not affected. TPMT enzyme plays an important role in the inactivation of this excess drug. An inverse relation exists between TPMT activity and TGN levels, i.e., patients with high TPMT activity exhibits low levels of TGN nucleotides at normal doses; whereas, in case of patients with low TPMT activity, the TGN's accumulate in the body even at normal doses. And therefore, a better drug dose for these patients would be $1 / 10$ of the drug dosage as compared to the other patients.

The TPMT activity depends on the TPMT genotype. TPMT gene, located on chromosome $6 \mathrm{p} 22.3$ is $5 \mathrm{Kbp}$ long with 10 exons [10]. More than 10 non-functional mutant alleles for TPMT have been reported to be associated with inheritance of TPMT deficiency till date [4]. Of these, TPMT*2 (G238C), TPMT*3A (combined appearance of G460A and A719G), TPMT*3B (G460A) and TPMT*3C (A719G) have been observed to the most prevalent gene variants [4]. TPMT deficiency inherited by these mutant alleles is associated with lower cellular levels of TPMT protein and these proteins are degraded more rapidly by an ATP-dependent proteasome-mediated pathway [9]. There is no data available on TPMT gene in Indian patients.

Also, 5-FU is one of the most frequently prescribed chemotherapeutic drugs for the treatment of cancers of the gastrointestinal tract, breast, head and neck [2]. Dihydropyrimidine Dehydrogenase (DPD) enzyme catabolizes $80 \%$ to $90 \%$ of 5 -FU dose to the inactive 5,6-dihydro-5-fluorouracil [11]. However, a decreased DPD activity is associated with more than 4-fold risk of severe or fatal toxicity from standard doses of 5-FU. This decreased or nil activity of DPD enzyme is the result of genetic variations in the DPD gene located on chromosome 1 . It is a $834 \mathrm{Kbp}$ gene with 23 exons [1]. About 20 allelic variants have been identified along the entire length of the DPD gene. However, many of these variations have not been definitely associated with altered DPD activity. Similarly, not all toxicity to 5-FU from reduced DPD activity can be explained by the currently known polymorphisms. However, a splice-site variant IVS14 $+1(\mathrm{G} \rightarrow \mathrm{A})$ in intron 14 has been reported to be the most abundant [1] and clinically relevant resulting in truncated protein, leading to deletion of $165 \mathrm{bp}$ in the RNA and subsequent elimination of the fluorouracil binding site in the protein, thereby giving rise to low DPD activity and severe 5-FU toxicity. The frequency of this variant in Caucasians has been reported to be $0.9 \%$ [12]. But, to date, no studies have been reported in Indian patients describing the analysis of DPD gene.

Because of the clinical significance of the TPMT and DPD genetic polymorphisms, the development of DNA-based diagnostic tests would be essential to determine the common TPMT/DPD variant alleles responsible for low activity. Also, since there are no studies done on TPMT/DPD gene in Indian patients, till date, the present study, aimed at the development, validation and application of PCR-based methods for the detection of common TPMT (G238C, G460A and A719G) and DPD $[\mathrm{IVS} 14+1(\mathrm{G} \rightarrow \mathrm{A})]$ genetic variations in the genomic DNA of Indian patients.

\section{Materials and methods}

\subsection{Subjects}

\subsubsection{TPMT gene study}

Venous blood from 30 patients with ALL (77\%)/Inflammatory bowel disease $(20 \%)$ and Langerhans cell histiocytosis (3\%) from P.D.Hinduja National Hospital \& Medical Research Centre (Mumbai, India), who were receiving 6-MP treatment at an average dose over a period of 6 months, were collected in blood collection tubes containing Ethylenediaminetetracetic acid (EDTA).

\subsubsection{DPD gene study}

EDTA blood samples were collected from 100 patients with breast cancer $(66 \%)$, cancer of stomach $(5 \%)$, colon cancer $(13 \%)$, squamous cell carcinoma (4\%), adenoid cystic carcinoma (1\%), cancer of sigmoid and rectum (8\%) and cancer of esophagus (3\%). These patients were on 5-FU based chemotherapy over a period of 6 months. 
The local ethics committee approved the study and an informed consent was obtained from all patients. The study conforms with The Code of Ethics of the World Medical Association (Declaration of Helsinki), printed in the British Medical Journal (18 July 1964).

\subsection{DNA extraction}

DNA was isolated by Miller et al. salting out procedure [16] with minor modifications.

\subsection{TPMT genotyping}

\subsubsection{Detection of G238C polymorphism}

G238C mutation has been detected using the allelespecific PCR assay [3]. The common primer used in the reaction was 5'TAA ATA GGA ACC ATC GGA CAC3'; the normal primer-5'GTA TGA TTT ATG CAG GTT TG3', and the mutant primer was 5'GTA TGA TTT TAT GCA GGT TTC3' [3]. The $50 \mu$ l PCR reaction mixture consisted of 25 pmoles primers, $200 \mu \mathrm{m}$ dNTP's, $1 \mathrm{mM} \mathrm{MgCl}{ }_{2}$ and 2 units of Hot star Taq polymerase enzyme (MBI Fermentas). 30 cycles of PCR were performed each consisting of 15 minutes of denaturation, followed by 1 minute of annealing at $54^{\circ} \mathrm{C}$ and 1 minute of extension at $72^{\circ} \mathrm{C}$. The procedure was completed by the continuation of the last $72{ }^{\circ} \mathrm{C}$ incubation for a further 10 minutes. Electrophoresis of the PCR products were carried out on $4 \%$ agarose gel, stained with ethidium bromide and visualized under UV light.

\subsubsection{Detection of G460A polymorphism}

The amplification was carried out using primers that created the Mwo I restriction site in the wild type allele [3]. The primers F-5' ATA ACA GAG TGG GGA AGG CTG C3' and R- 5'CTA GAA CCC AGA AAA AGT ATA G3' [3] were annealed at $60^{\circ} \mathrm{C}$ for $40 \mathrm{sec}-$ onds, extended at $72^{\circ} \mathrm{C}$ for 43 seconds, with 2 units of hot star Taq polymerase (MBI Fermentas, Genetix Biotech Asia Private Limited, New Delhi, India) and denatured at $94^{\circ} \mathrm{C}$ for 15 minutes, for a total of $30 \mathrm{cy}-$ cles, with a final extension of 5 minutes at $72^{\circ} \mathrm{C}$, in the eppendorf thermal cycler. The amplified DNA was digested with 10 units of Mwo I restriction enzyme (MBI Fermentas) overnight at $37^{\circ} \mathrm{C}$, size fractionated on $4 \%$ agarose gels at 90 volts for 1.5 hours and visualized under ultraviolet (UV) light after staining with ethidium bromide. Positive control for G460A mutation (kindly provided by Dr. Guiliana Decorti, Italy) and negative control were included in each assay.

\subsubsection{Detection of A719G mutation}

A719G mutation was detected using primers F-5, AAT CCC TGA TGT CAT TCT TCA TAG TAT TT 3' and R-5' CAC ATC ATA ATC ATA ATC TCC TCT TCC 3', which created Acc I restriction site in the mutant allele [8]. The primers were annealed at $50^{\circ} \mathrm{C}$ for 1 minute, extended at $72^{\circ} \mathrm{C}$ for 2 minutes, for a total of 35 cycles, with a final extension of 10 minutes at $72^{\circ} \mathrm{C}$, in the eppendorf thermal cycler. The amplified DNA was digested with 10 units of Acc I restriction enzyme (MBI Fermentas) overnight at $37^{\circ} \mathrm{C}$, size fractionated on $4 \%$ agarose gels at 90 volts for 1.5 hours and visualized under UV after staining with ethidium bromide. Positive control for A719G mutation (kindly provided by Dr. Guiliana Decorti, Italy) and negative control were included in each assay.

\subsection{DPD genotyping}

2.4.1. Detection of $[I V S 14+1(G \rightarrow A)]$ polymorphism PCR amplification of intron 14 of the DPD gene for the identification of [IVS14 $+1(\mathrm{G} \rightarrow \mathrm{A})]$ polymorphism was carried out in a $50 \mu \mathrm{l}$ reaction mixture containing $10 \mathrm{mM}$ Tris $\mathrm{HCl}(\mathrm{pH} 8.3), 50 \mathrm{mM} \mathrm{KCl}, 2 \mathrm{mM}$ $\mathrm{MgCl}_{2}, 50$ pmoles each primer (F-5' GAA CCA CCT CTG GCC CCA CGT ATG 3'; R-CAG CAA AGC AAC TGG CAG ATT C 3') [15], $200 \mu \mathrm{m}$ each Deoxynucleotide triphosphate (dNTP's) and 2.5 units of Taq Polymerase. After initial denaturation at $94{ }^{\circ} \mathrm{C}$ for 5 mins, amplification was carried out for 35 cycles ( $94^{\circ} \mathrm{C}$ for $1 \mathrm{~min}, 58^{\circ} \mathrm{C}$ for $1 \mathrm{~min}, 72^{\circ} \mathrm{C}$ for $2 \mathrm{mins}$ ). The PCR products were separated on $4 \%$ agarose gels, visualized with ethidium bromide. Restriction analysis of the PCR products were performed in a $10 \mu \mathrm{l}$ reaction mixture containing $10 \mathrm{mM}$ Tris $\mathrm{HCl}(\mathrm{pH} 7.4), 100 \mathrm{mM}$ $\mathrm{NaCl}, 10 \mathrm{mM} \mathrm{MgCl} 2,0.1 \mathrm{mM}$ EDTA, $1 \mathrm{mM}$ dithiothreitol, $7 \mu \mathrm{l}$ PCR product and 10units of restriction endonuclease TaiI. The mixture was incubated overnight at $37^{\text {circ }} \mathrm{C}$. The DNA fragments were subsequently analyzed on $4 \%$ agarose gels and visualized with ethidium bromide.

\subsection{DNA sequencing}

The assays were validated by subjecting the double stranded PCR products to automated bi-directional DNA sequencing (Bangalore Genei, India). The sequencing primers used were the same as the PCR primers. The sequences obtained were matched with the published TPMT gene sequence (Genbank accession No. AB045146) and DPD gene sequence (Genbank accession No. U20938). 


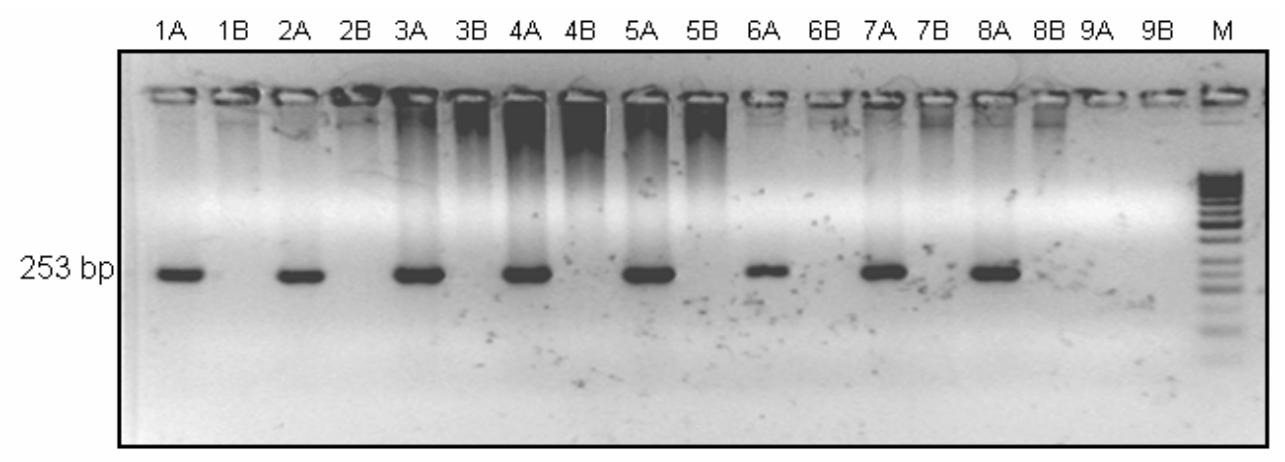

Fig. 1. DNA samples showing amplification with wild type and common primers (lanes 1A, 2A, 3A, 4A, 5A, 6A, 7A, 8A) due to the presence of wild type genotype ( $253 \mathrm{bp}$ ); whereas, no amplification was observed with mutant and common primers (lanes $1 \mathrm{~B}, 2 \mathrm{~B}, 3 \mathrm{~B}, 4 \mathrm{~B}, 5 \mathrm{~B}, 6 \mathrm{~B}, 7 \mathrm{~B}, 8 \mathrm{~B}$ ), indicating the absence of any mutant allele. Lanes 9A, 9B - Negative controls without DNA; M - Molecular weight marker.

\section{Statistics}

For diagnostic significance analysis, calculations were made as follows: test sensitivity $=\mathrm{RP} /(\mathrm{RP}+\mathrm{FN})$, test specificity $=\mathrm{RN} /(\mathrm{RN}+\mathrm{FP})$, test efficiency $=$ $(\mathrm{RP}+\mathrm{RN}) /(\mathrm{RP}+\mathrm{FN}+\mathrm{FP}+\mathrm{RN})$ and positive predictive value $=\mathrm{RP} /(\mathrm{RP}+\mathrm{FP})($ abbreviations: $\mathrm{RP}$ - right positive, FP- false positive, RN- right negative, FN- false negative).

\section{Results}

\subsection{TPMT genotyping}

Genotyping was performed for four of the most common SNP's, viz; TPMT *2, *3A, *3B and *3C alleles in 30 patients on 6MP treatment. An allele-specific PCR assay was used for the screening of G238C polymorphism. A $253 \mathrm{bp}$ product is amplified with the mutant and common primers in the presence of mutant G238C polymorphism, whereas, in case of the wild type genotype, a $253 \mathrm{bp}$ product is amplified with normal and common primers (Fig. 1).

Restriction enzyme based PCR assays were carried out for screening G460A and A719G polymorphisms. In case of G460A polymorphisms, MwoI digestion of wild type DNA yields fragments of 267 and $98 \mathrm{bp}$, whereas, DNA containing G460A mutation remains undigested, yielding an uncleaved fragment of $365 \mathrm{bp}$ (Fig. 2). The A719G polymorphism introduces an AC$\mathrm{CI}$ restriction site in the amplified fragment and yields fragments of 207 and $86 \mathrm{bp}$. Wild type DNA remains uncleaved with 293 bp (Fig. 3).

One of the patients having Langerhans cell histiocytosis with diabetes and exhibiting neutropenia on 6-

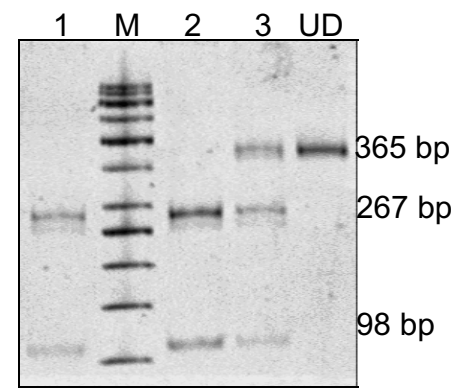

Fig. 2. Mwo I digestion of wild type DNA (lanes 1,2) yielded fragments of $267 \mathrm{bp}$ and $98 \mathrm{bp}$, whereas, the heterozygous G460A mutation positive control DNA sample (lane 3) shows undigested 365 bp fragment, along with the 267 bp and 98 bp fragments. UD undigested PCR product; $\mathrm{M}$ - Molecular weight marker.

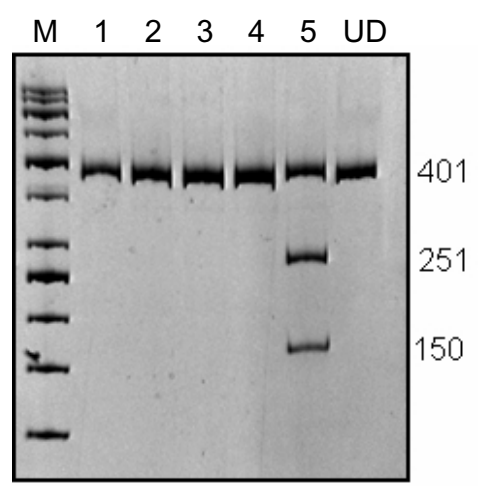

Fig. 3. A719G heterozygous control DNA sample (lane 5) with Acc I restriction site yielded fragments of $251 \mathrm{bp}$ and $150 \mathrm{bp}$, along with the undigested 401 bp fragment; whereas, wild type DNA samples yielded uncleaved 401 bp fragment. UD - undigested PCR product; $\mathrm{M}$ - Molecular weight marker.

MP treatment was found to be homozygous for G460A polymorphism. Whereas, two patients with ALL, showing side-effects on 6-MP treatment were found to pos- 


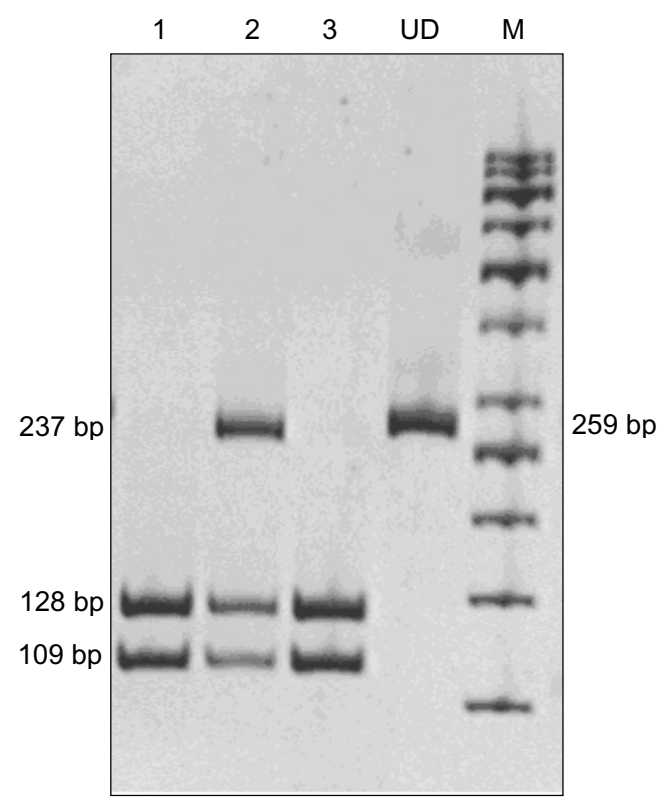

Fig. 4. [IVS14 $+1(\mathrm{G} \rightarrow \mathrm{A})]$ heterozygous control DNA sample (lane 2) with TaiI restriction site yielded fragments of $237 \mathrm{bp}$ and $128 \mathrm{bp}$ and 109, whereas, wild type DNA samples yielded $128 \mathrm{bp}$ and 109 bp fragments. Undigested (UD) product is $259 \mathrm{bp} . \mathrm{M}-$ Molecular weight marker.

sess wild-type alleles for the common TPMT variations screened. Also, 2 patients showing side-effects during 6-MP treatment and responding well to the same drug at a later stage, also showed the presence of wild-type allele.

\subsection{DPD genotyping}

$[\operatorname{IVS} 14+1(\mathrm{G} \rightarrow \mathrm{A})]$ polymorphism was genotyped by digesting the 258 bp PCR product with Tail restriction enzyme. After digestion, the wild type allele gave rise to fragments of 128,109 and $21 \mathrm{bp}$. In contrast, the PCR fragment containing the $\mathrm{G} \rightarrow \mathrm{A}$ point mutation in the invariant splice donor site of exon 14 produced 2 fragments of $237 \mathrm{bp}$ and $21 \mathrm{bp}$ (Fig. 4).

The reliability of these genotyping assays were confirmed by sequencing the PCR products (Fig. 5).

\section{Discussion}

TPMT polymorphisms have considerable clinical importance because it is responsible for the toxicity of Thiopurine drugs, producing potential life-threatening complications like myelosuppression, bone marrow toxicity, leucopenia, pancytopenia, etc. Identification of these polymorphisms not only provide important insights into the molecular mechanisms of these genetic polymorphisms, but also offers a method to prospectively identify the TPMT-deficient patients prior to treatment with potentially toxic dosages of Thiopurine drugs [7]. Thus, the present study focuses on developing a molecular assay for the identification of the most prevalent $\mathrm{TPMT} * 2, * 3 \mathrm{~A}, * 3 \mathrm{~B} \& * 3 \mathrm{C}$ mutant alleles, so as to enable the clinicians to optimize the thiopurine therapy. These mutant alleles account for approximately $95 \%$ of deficiency-causing alleles, so the sensitivity of genotyping for detecting these TPMT deficiencies is high.

Of the 30 patients screened during the study for TPMT variations, one of the patient exhibited a homozygous G460A allele. This patient had Langerhans cell histiocytosis with diabetes. On 6-MP treatment, he experienced neutropenia. The severe toxicity along with homozygous G460A polymorphism made the clinician stop the 6-MP treatment immediately and subsequently the patient showed marked health improvement. However, two of the patients with ALL showing severe 6-MP side-effects exhibited wild-type alleles for all the prevalent TPMT mutant alleles, indicating the presence of some other rare unidentified mutant variants in these patients. This suggests the presence of allelic heterogeneity and variation in allele frequencies among different ethnic and racial groups. This is also in accordance with a study carried out by Otterness et al. [4]. As mentioned in the previous studies [7], the identification of as many additional variant alleles for low activity as possible will therefore be required to extract all the Indian patients at risk for thiopurine toxicity. Also, in two patients, it was observed that they exhibited 6-MP side-effects, but responded well to the same drug at a later stage. These patients, as expected were found to possess wild-type allele for all the common TPMT variants, clearly suggesting that the adverse effects caused by the thiopurine treatment could be attributable to multifactorial phenomena involving multiple biological and environmental processes (including drug interactions), other than the mutated genotype alone. Thus, though genotyping is useful in identifying patients with risk for thiopurine toxicity, the clinicians will need to monitor the patients for the other common forms of toxicity.

Also, the [IVS14 $+1(\mathrm{G} \rightarrow \mathrm{A})]$ mutation in the DPD gene has been observed to adversely affect the donor splice site of intron 14, leading to deletion of $165 \mathrm{bp}$ in the RNA. This subsequently results in the elimination of a 55 amino acid long, fluorouracil binding site in the 


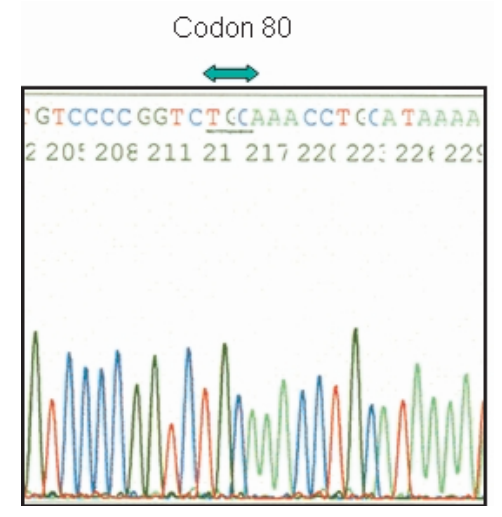

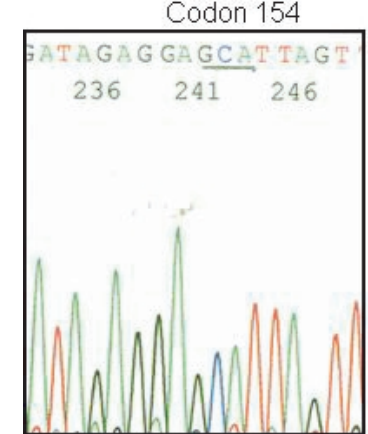

(b)

(a)

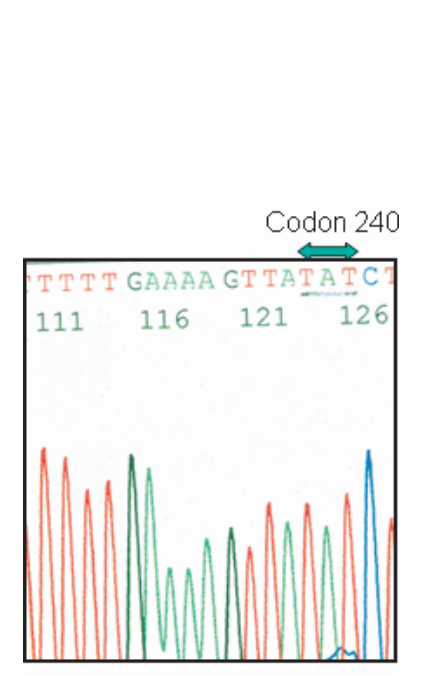

(c)

Presence of GT (intron 14) at the invariant splice donor site of exon 14. In case of mutant, GT gets replaced by AT

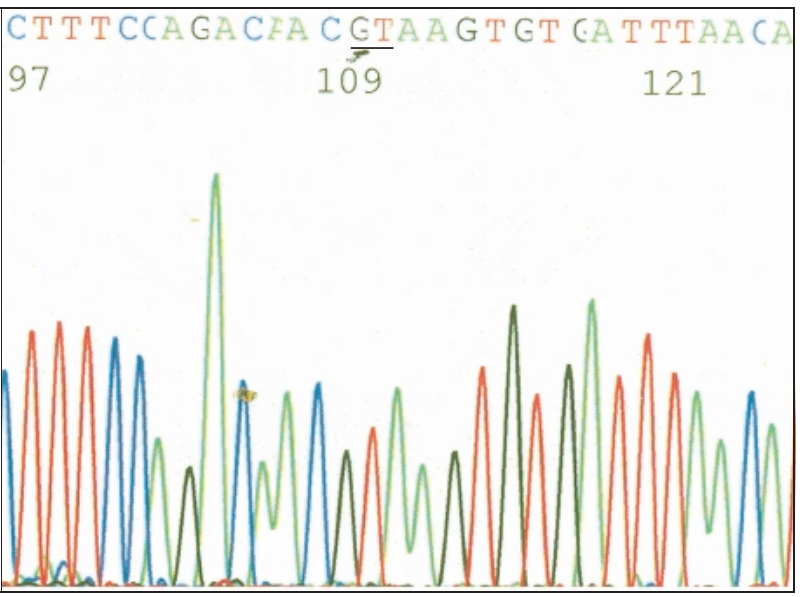

(d)

Fig. 5. (a) Reverse DNA sequence analysis for G238C mutation shows the presence of the gca (coding for alanine) at codon 80 of the TPMT gene. (b) DNA sequence analysis of G460A mutation shows the presence of gca (coding for alanine) at codon 154 of the TPMT gene. (c) DNA sequence analysis of A719G mutation shows the presence of tat (coding for tyrosine) at codon 240 of the TPMT gene. (d) DNA Sequencing showing the presence of GT in intron 14 at the invariant splice donor site of exon 14 in DPD gene. In case of mutant, GT gets replaced by AT.

DPD protein [6]. The high prevalence of this mutation and the high incidence of cases with severe lethal outcome following 5-FU treatment due to DPD-deficiency emphasizes the importance of [IVS14 $+1(\mathrm{G} \rightarrow \mathrm{A})]$ analysis. A molecular assay to rapidly detect this protein truncating alteration was established during this study to enable the clinicians to identify those patients supposed to be at risk for toxicity during 5-FU drug intake. Although, this mutation is very frequent, absence of this splice site mutation does not rule out the possibility of a decreased DPD activity due to another mutation. Approximately 20 variant alleles have been identified till date in the DPD gene. Identification of all the additional molecular alterations in Indian patients will be important to provide a high level of diagnostic and predictive ability to identify at-risk patients for 5 -FU toxicity [15].

Before the initiation of standard-dose thiopurine therapy, the measurement of erythrocyte TPMT activity is generally recommended. However, erythrocyte TPMT activity assays will not reflect the metabolic capacity of a deficient patient if the patient has received a blood transfusion from a donor with normal TPMT activity within the previous 3 months. In addition, misclassification is possible because TPMT activity can be induced under therapy with thiopurine drugs [13]. Also, measuring the level of DPD activity within the tumor itself may have predictive value in determining 
whether the tumor is likely to respond to 5-FU. However, the use of biochemical assays, although valuable is often not practical, particularly with the unavailability of sufficient clinical samples (e.g., needle biopsies). Molecular methodology can be an alternative methodology in such cases [14]. Genotyping, thus becomes an important diagnostic tool. Also, these methods require microgram quantities of DNA, which can be extracted for minimal whole blood samples. Since genotype of an individual does not change, it needs to be determined only once during the life-time, making this technique more clinically relevant and inexpensive. This is also in agreement with a study carried out by Yates et al. [3]. Identification of the additional TPMT/DPD genetic variations in Indian patients by DNA sequencing and incorporating them in a single pharmacogenomic assay in future clinical studies, will further improve the mutation detection rate, allowing the avoidance of any undesired treatment toxicity.

\section{Conclusion}

Considering the common use of 6MP and 5FU drugs in the treatment of cancer patients and the high prevalence of TPMT/DPD gene variations warrants genetic screening in cancer patients before administration of these drugs. In the present study, we have developed and validated simple, sensitive, reliable and accurate molecular assays that allows the determination of the common TPMT/DPD gene variations in TPMT/DPD deficient patients, who require a substantial reduction in doses and careful management of drug association to avoid toxicity, thereby, providing the concept of individualized therapy. These pharmacogenetic tests can allow the clinicians to make accurate diagnosis, prescribe more efficient drug therapies and avoid harmful side effects. This report certainly provides further stimulus for examining the potential utility of this assay as a predictive pharmacogenomic assay in future clinical studies.

\section{Acknowledgements}

The study was funded by the National Health and Education Society, P.D.Hinduja National Hospital \& Medical Research Centre, Mumbai, India. We thank Dr. Guiliana Decorti, Italy, for providing us with the G460A and A719G mutation positive control DNA samples used in this study. We also gratefully acknowl- edge Dr. Andre van Kuilenburg, Netherlands for providing us with the $[\operatorname{IVS} 14+1(\mathrm{G} \rightarrow \mathrm{A})]$ mutation positive control DNA samples. We are extremely thankful to Dr. Shivani Bhat (Clinical Assistant, Oncologist) and the nursing staff of Oncology Dept. for their kind help during sample collection. The authors have no potential conflicts of interest relevant to the contents of this manuscript.

\section{References}

[1] A.B.P. van Kuilenburg, J. Sajes, D.J. Richel, L. Zoetekouw, H.V. Lenthe, R.A. De Abreu, J.G. Maring, P. Vreken and A.H. van Gennip, Clinical implications of Dihydropyrimidine Dehydrogenase (DPD) deficiency in patients with severe 5Fluorouracil-associated toxicity: Identification of new mutations in the DPD gene, Clinical Cancer Research 6 (2000), 4705-4712.

[2] A.B.P. van Kuilenburg, E.W. Muller, J. Sajes, R. Meinsma, L. Zoetekouw, H.R. Waterham, F. Baas, D.J. Richel and A.H. van Gennip, Lethal outcome of a patient with a complete Dihydropyrimidine Dehydrogenase (DPD) deficiency after administration of 5-Fluorouracil: Frequency of the common IVS14+1G $>$ A mutation causing DPD deficiency, Clinical Cancer Research 7 (2001), 1149-1153.

[3] C.R. Yates, E.Y. Krynetski, T. Loennechen, M.Y. Fessing, H. Tai, C. Pui, M.V. Relling and W.E. Evans, Molecular diagnosis of thiopurine S-methyltransferase deficiency: Genetic basis for Azathioprine and Mercaptopurine intolerance, Annals of Internal Medicine 126 (1997), 608-614.

[4] D. Otterness, B.S.C. Szumlanski, B.S.L. Lennard, B. Klemetsdal, J. Aarbakke, J. Ok Park-Hah, H. Iven, K Schmiegelow, E. Branum, J. O'Brien, R. Weinshilboum, Human thiopurine methyltransferase pharmacogenetics: Gene sequence polymorphisms, Clin Pharmacol Ther 62 (1997), 60-73.

[5] E. Topic, Pharmacogenetic and tumor drugs - 2005 http:// www.ifcc.org/ejifcc/vol16no2/160206200512.htm

[6] E. Gross, K. Seck, S. Neubauer, J. Mayr, H. Hellebrand, A. Ratanaphan, V. Lutz, H. Stokinger and M. Kiechle, High throughput genotyping by DHPLC of the Dihydropyrimidine Dehydrogenase gene implicated in (fluoro)pyrimidine catabolism, International Journal of Oncology 22 (2003), 325-332.

[7] E.Y. Krynetski, J.D. Schuetz, A.J. Galpin, C. Pui, M.V. Relling and W.E. Evans, A single point mutsion leading to loss of catalytic activity in human thiopurine S-Methyltransferase, Proceedings of National Academy of Sciences USA 92 (1995) 949-953.

[8] G. Stocco, S. Martelossi, G. Decorti, A. Ventura, N. Malusaq, F. Biartoli and T. Giraldi, Pharmacogenetics of thiopurines: can posology be guided by laboratory data, Radiol Oncol $\mathbf{3 8}$ (2004), 101-109.

[9] H. Tai, E.Y. Krynetski, E.G. Schetz, Y. Yanishevski and W.E. Evans, Enhanced proteolysis of thiopurine Smethyltransferase (TPMT) encoded by mutant allele in humans (TPMT *3A, TPMT*2): Mechanisms for the genetic polymorphism of TPMT activity, Proceedings of National Academy of Sciences USA 94 (1997), 6444-6449.

[10] J.T. Chowning, Pharmacogenetics. Treating disease using an understanding of genetics, from http://www.nwabr.org/ education/pdfs/Pharmacogenetics/TPMT_LESSON.pdf 
[11] M.R. Johnson, K. Wang and R.B. Diasio, Profound Dihydropyrimidine Dehydrogenase Deficiency resulting from a novel compound heterozygote genotype, Clincal Cancer Research 8 (2002), 768-774.

[12] M. Raida, W. Schwabe, P. Hausler, A.B.P. Van Kuilenburg, A.H. Van Gennip, D. Behnke and K. Hoffken, Prevalence of a common point mutation in the Dihydropyrimidine Dehydrogenase (DPD) gene within the 5'-splice donor site of intron 14 in patients with severe 5-Fluorouracil (5-FU)-related toxicity compared with controls, Clinical Cancer Research 7 (2001), 2832-2839.

[13] N. von Ahsen, V.W. Armstrong and M. Oellerich, Rapid, long-range molecular haplotyping of Thiopurine Smethyltransferase (TPMT) $* 3 \mathrm{~A}, * 3 \mathrm{~B}$ and $* 3 \mathrm{C}$, Molecular
Diagnostics and Genetics 50 (2004), 1528-1534.

[14] R.B. Diasio and M.R. Johnson, Dihydropyrimidine Dehydrogenase : Its role in 5-Fluorouracil Clinical Toxicity and Tumor Resistance, Clinical Cancer Research 5 (1999), 2672-2673.

[15] S.A. Ridge, J. Sludden, O. Brown, L. Robertson, X. Wei, A. Sapone, P.M. Fernandez-Salguero, F.J. Gonzalez, P. Vreken, A.B.P. van Kuilenburg, A.H. van Gennip and H.L. McLeod, Dihydropyrimidine Dehydrogenase pharmacogenetics in Caucasian subjects, British Journal of Clinical Pharmacology 46 (1998), 151-156.

[16] S.K. Miller, D.D. Dykes and H.F. Polesky, A simple salting out procedure for extracting DNA from human nucleated cells, Nucleic Acids Res 19 (1998), 1215. 


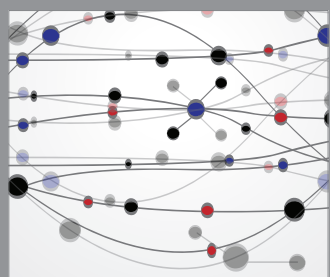

The Scientific World Journal
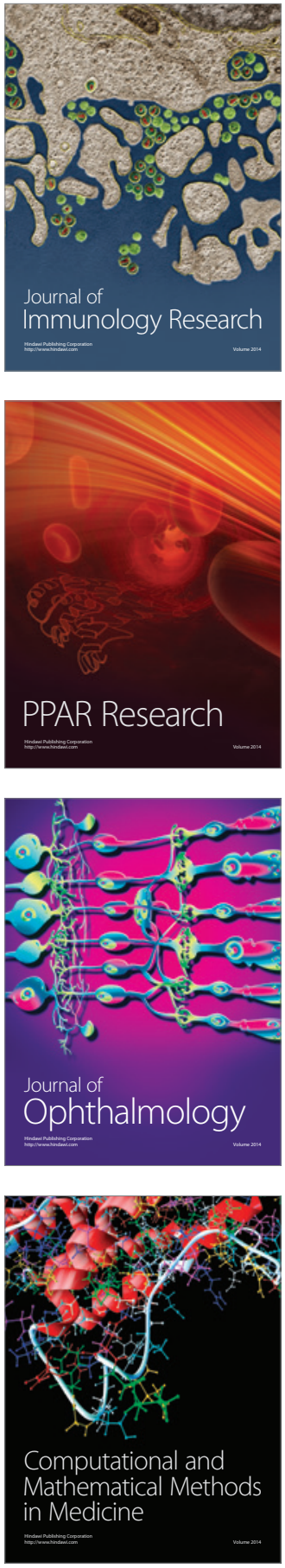

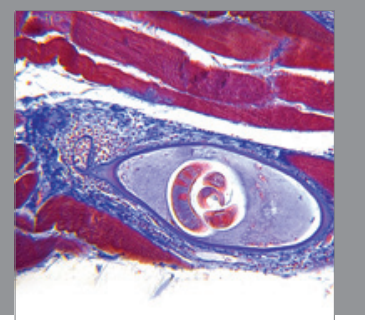

Gastroenterology

Research and Practice
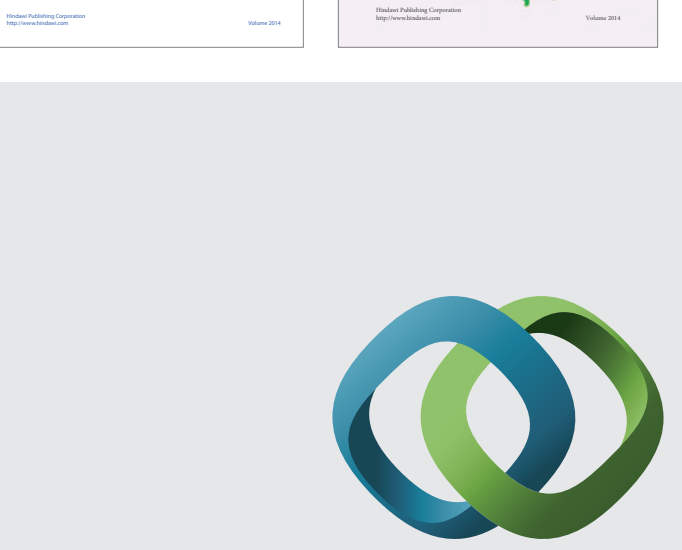

\section{Hindawi}

Submit your manuscripts at

http://www.hindawi.com
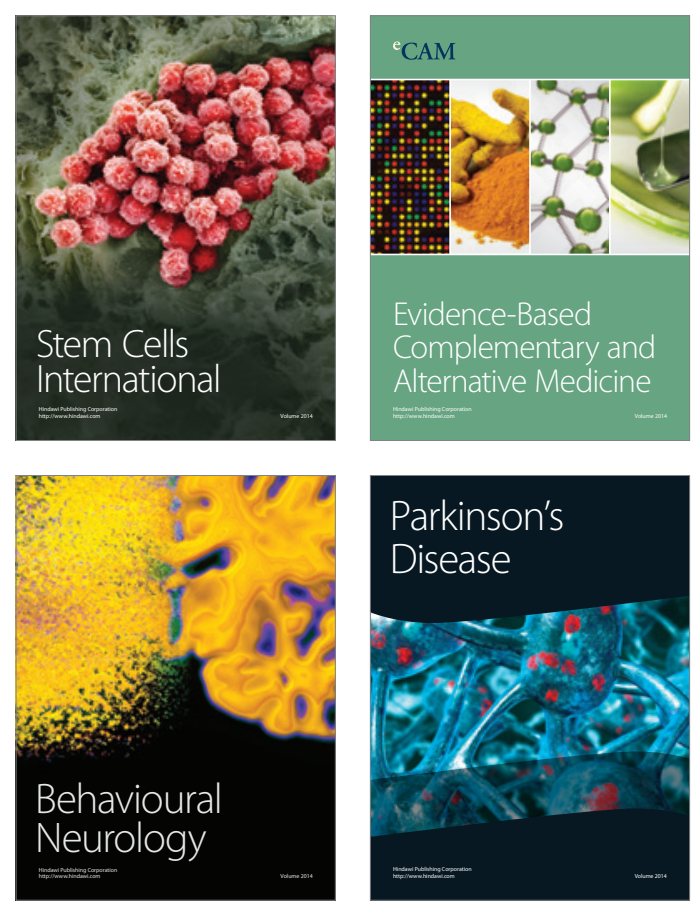

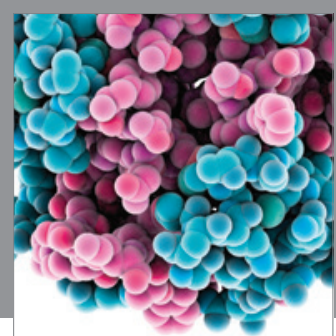

Journal of
Diabetes Research

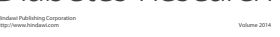

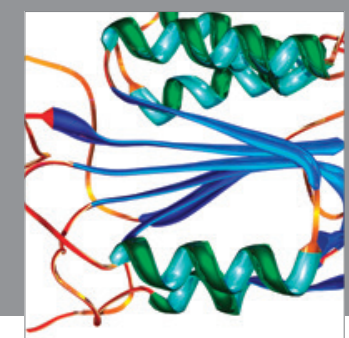

Disease Markers
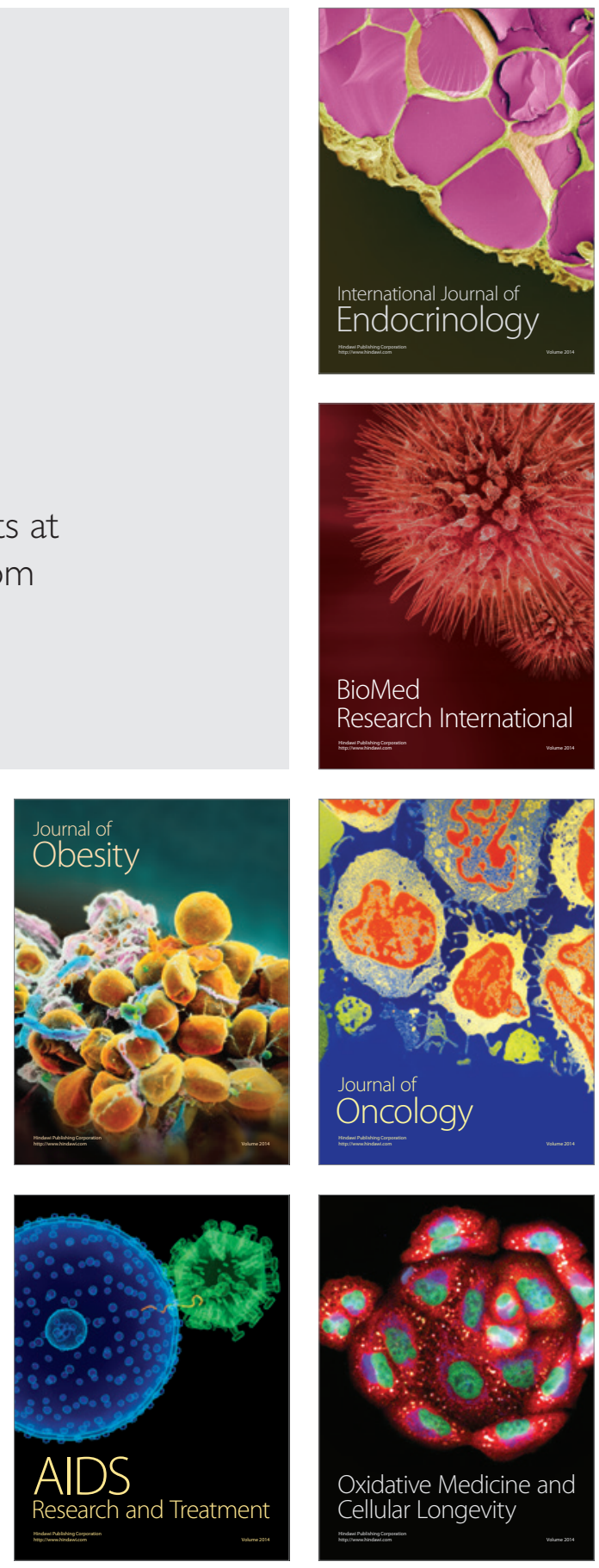